\title{
CONTRACEPÇÃO FEMININA E POLÍTICA PÚBLICA NO BRASIL: PONTOS E CONTRAPONTOS DA PROPOSTA OFICIAL*
}

\author{
Augusta Thereza de Alvarenga \\ Néia Schor ${ }^{\star \star *}$
}

Resumo: O presente trabalho busca retraçar como a questão da contracepção feminina é publicizada na mídia, a partir de matéria veiculada em dois matutinos paulistas e um carioca. Procura demonstrar como interesses econômicos, políticos e ideológicos estão presentes no interior do próprio Estado e da sociedade civil caracterizando, sobretudo na conjuntura 1984-1993, a indefinição de uma política para o setor centrado na polêmica planejamento familiar versus controle da natalidade. A conjuntura pós 93 redefine a discussão enfatizando, com base nos preceitos defendidos na Conferência do Cairo 94 sobre direitos reprodutivos, a questão do direito ao aborto e à esterilização feminina legalizados.

Palavras-chave: anticoncepção; planejamento familiar; controle de natalidade; saúde da mulher; saúde reprodutiva; aborto; esterilização cirúrgica

* Versão revista e atualizada de palestra proferida no "Simpósio Franco-Brasileiro sobre Prevenção da Mortalidade Materna com Ênfase na Gravidez na Adolescência", São Paulo, 1992 (ALVARENGA, 1992)

** Socióloga, Professora Doutora do Departamento de Saúde Materno Infantil da Faculdade de Saúde Pública da Universidade de São Paulo. E-mail atal@usp.br

*** Enfermeira Sanitarista, Professora Associada do Departamento de Materno Infantil da Faculdade de Saúde Pública da Universidade de São Paulo. E-mail nschor@usp.br 


\section{SOBRE O EIXO DE ANÁLISE}

A questão da discussão da contracepção feminina no Brasil como política pública oficial na área da Saúde Reprodutiva adquire particular interesse quando analisada a partir da forma como é problematizada na mídia quer por setores do governo, quer da sociedade civil. Isto porque, traduz a forma típica de como problemas sociais passam a caracterizarse como questão pública, notadamente de natureza sócio-político e ideológica.

Da ótica que pretendemos enfocar a presente temática, o eixo teórico adotado permite resgatar e, ao mesmo tempo, negar a concepção corrente de que em nossa sociedade - a brasileira - a família é colocada na esfera do privado e, com isso, sua "privacidade" é, portanto, defendida da interferência do Estado, de maneira indiferenciada para todas as classes sociais, nos assuntos que the dizem respeito.

Ao lado de pequenas evidências, que demonstram que o Estado controla a existência familiar, observa-se, no caso da contracepção feminina, uma certa tendência à ruptura do que consideramos como "Posição Liberal" frente à intervenção do Estado na Esfera do Privado, para as chamadas camadas populares, no que se refere particularmente à livre reprodução biológica e definição ou opção pelo número da prole.

Essa faixa de "flexibilização" da posição liberal, que abre perspectivas para potencialmente permitir essa interferência do Estado no privado (familiar), passa a ser manifestada no próprio processo de discussão sobre a política de controle da reprodução biológica, levado à cabo pela sociedade brasileira, notadamente a partir dos anos 80 , quando a questão é publicamente problematizada em termos de duas tendências típicas, que envolvem segmentos do Estado e da Sociedade Civil.

Ou seja, por um lado, o Estado apresentando-se como espaço de luta pela hegemonia do poder, onde se contrapõem os interesses de classe (econômico, político e ideológico) perfila, em seu interior, duas propostas qualitativamente diferenciáveis para o setor, uma de "planejamento familiar", fundada em preceitos médicos e de política de saúde pública e, outra, de "controle de natalidade", com seus pressupostos demográficos e de política populacional e econômica; por outro lado, essas duas tendências, como manifestações de interesses de classe no setor, inscrevem-se num espaço de luta intra Estado (com adesões diferenciadas entre Ministérios, Câmara de Deputados e Senado Federal) e entre Estado e Sociedade Civil (com destaque, para esta última, das associações de classe e de movimentos populares). 
As possibilidades de manifestação dessas duas posições "polares" frente à questão da reprodução humana se dá, sobretudo, na década de 80 , notadamente a partir de 1984. No entanto, a gênese desse processo apresenta-se - de maneira evidente - na década imediatamente anterior, o que nos leva a caracterizá-la como período de transição entre duas conjunturas bastante características de dois modos de atuação do Estado no setor. A década de 90 redesenha a tendência, sobretudo após a Conferência do Cairo 94.

\section{CARACTERIZANDOCONJUNTURAS}

A primeira conjuntura, de 1965 a 1974, inscrita num regime de exceção, é definida por um Estado pró-natalista, defensor de uma concepção desenvolvimentista de ocupação de espaços, muito embora bastante permissivo, tolerante mesmo, à atuação de clínicas privadas de "planejamento familiar" no país, cujo caso típico refere-se à presença da BENFAM, a partir de 1965, em solo nacional(CANESQUI, 1984, 1985; ROCHA, 1989). A segunda conjuntura, a partir de 1984, chega, notadamente até 1993, marcada pela posição ambígua do Estado frente à assunção, de fato, de uma política nacional, ou de "planejamento familiar", ou de "controle da natalidade". Tendência diferente observa-se na última conjuntura pós 93 pela descaracterização da discussão em termos polares. Nesse particular, foi marcante a busca de inserção da discussão da questão da contracepção num contexto mais amplo, definido pela Conferência Mundial de População e Desenvolvimetno realizada na cidade do Cairo, em 1994 (WELTI, 1997), onde os direitos reprodutivos e a questão de gênero ocupa lugar de destaque na definição dos pontos a serem enfocados. Consagra-se, neste contexto, a área da Saúde Reprodutiva que passa a incorporar o homem como elemento integrante dadas as relações de gênero. (CORRÊA \& PETCHESKY, 1996)

Assim também, como fase de transição, o período de 1974 a 1984 é igualmente delimitado pela presença de duas grandes Conferências Mundiais de População, a primeira realizada em Bucarest (1974) e a segunda na cidade do México (1984) (ARAICA, 1997). Atuam como marco pelo tipo de posicionamento diferenciado assumido pelo Brasil nas mesmas e pela conjuntura econômica, política e social na qual se inserem no interior da sociedade brasileira.

O início da década de 70 tem, em 1974, conjuntura bastante típica, caracterizada como momento de inflexão da economia brasileira e conhecida como "Fim do Milagre Brasileiro". Acentuada pela crise internacional do petróleo essa conjuntura trás, em seu bojo, ao lado da diminuição do crescimento do PIB (Produto Interno Bruto), uma retração na taxa de emprego e uma acentuada diminuição do salário mínimo real, com cerca de 
$18 \%$ da população brasileira vivendo em miséria absoluta (FIORI \& KORNIS, 1994; LOPES \&.GOTTESCHALK, 1990).

Como tentativa de superação dessa conjuntura de crise o governo busca avançar em medidas de política social visando a legitimá-lo, através de uma ampliação da assistência à saúde da população (BRAGA \& PAULA, 1981; LUZ, 1979).

No entanto, ao lādo das medidas em política social, vale destacar que o governo procura, igualmente, investir em uma política demográfica que, em tese, apresenta-se qualitativamente diferenciada daquela "pró-natalista" defendida em períodos anteriores, conforme indica o texto do II PND (Plano de Desenvolvimento Social), de 1974.

Sustentando a hipótese de que essa conjuntura marca o início de um processo de mudança da concepção do Estado acerca da questão da política de reprodução humana, recorremos, igualmente, ao discurso do então Ministro da Relações Exteriores, junto ao Governo Geisel, Embaixador Antônio Azevedo da Silveira, quando afirma: "Poder recorrer às medidas de controle da natalidade não deve ser privilégio reservado às famílias abastadas e, portanto, é responsabilidade do Estado proporcionar a informação e os meios que possam ser necessários às famílias de renda limitada". Por outro lado, a existência de dezoito Projetos de Lei, tramitados na Câmara dos Deputados, no período, sinalizam, também, essa tendência. Como ilustrativo destacam-se, em termos de propósitos, não só a busca de alteração do Art. 20 da Lei de Contravenções Penais (que verșava sobre propaganda referente a métodos de evitar a gravidez), transformado, em 1974, pelo Senado, em Norma Jurídica, Lei N. $006734^{1}$. mas, igualmente, as diferentes tentativas para a criação de programas de planejamento familiar e distribuição de métodos contraceptivos à população de baixa renda. Digno de nota é a existência, no período, de uma CPI (Comissão Parlamentar de Inquérito) no Senado Federal, criada com o objetivo de investigar problemas vinculados ao aumento populacional brasileiro; desenvolvida principalmente no ano de 1983, teve suas conclusões apresentadas em novembro de 1984, acompanhadas de um Projeto de Lei (N.․ 267, dezembro de 1984) proposto por Mário Mota (PMDB / Acre) e Almir Pinto (PDS / Ceará), respectivamente, Presidente e Relator da Comissão. Este Projeto, que dispunha sobre uma "Política Nacional de População e Planejamento Familiar", embora arquivado teve, segundo ROCHA (1983), grandes desdobramentos no período seguinte.

$1 \mathrm{O}$ referido artigo manteve a proibição referente ao anúncio de "processo, substância ou objeto destinado a provocar aborto" 


\section{A CONJUNTURA 1984-1993}

Buscando caracterizar a conjuntura 1984-1993, como contexto onde emerge uma postura ambígua do Estado brasileiro frente à definição de uma Política de Planejamento Familiar para o país, a posição do Brasil na Conferência Mundial sobre População, realizada na Cidade do México em agosto de 1984, defendida pelo então Ministro da Saúde, Waldir Arcoverde, coloca-se como ponto de partida necessário. Isto porque, muito embora, nesse momento, esta se apresente com a aparência de oficial não é, no interior do Estado brasileiro, posta (ou assumida) como tal, pelas contradições que se manifestam no período.

Presente em documento oficial do Ministério da Saúde esta, enquanto proposta de inscrição do planejamento familiar como parte de uma assistência integral à saúde da mulher (MINISTÉRIO DA SAÚDE, 1983a;b), ganha corpo no setor saúde pública tendo como defensores, ao lado de técnicos da área, vários segmentos da Sociedade Civil.

No entanto, longe de constituir-se numa posição de consenso, tal proposta é, senão negada, totalmente "ignorada" por parte de outros setores do governo. Fato ilustrativo foi a posição assumida, publicamente, pelo então Ministro Chefe do Estado Maior das Forças Armadas (EMFA), Tenente Brigadeiro - do - ar Waldir Vasconcelos, em setembro de 1984, um mês, portanto, após o suposto posicionamento do Brasil na Conferência Mundial de População, no México.

Declara, através do Matutino Paulista O Estado de São Paulo (14-09-1984, p.9), em matéria intitulada "Planejamento Familiarlogo terá decreto", que um Grupo Interministerial apresentaria à Presidência da República os estudos finais para a elaboração de um Decreto-Lei visando a criar uma política demográfica nacional, estudo esse - ao que parece apoiado nos resultados da CPI do Senado. Acrescenta que o referido decreto entraria em vigor no ano de 1985, com a criação da chamada "Comissão Nacional de População", que seria subordinada à Secretaria do Conselho de Segurança Nacional (CNS). A essa Comissão caberia a função de executar uma política demográfica, que previa a orientação da população, principalmente a pertencente às classes mais baixas, sobre o controle do número de filhos, além do fornecimento dos meios anticoncepcionais "livremente adotados", no entanto. A justificativa oferecida pelo Ministro, para a regulamentação via decreto-lei, ao invés de um projeto de lei, foi a da sobrecarga do trabalho dos parlamentares ${ }^{2}$.

2 Vale lembrar que essa informação precede, em cerca de três meses, o Projeto de Lei N. 267 tramitado no Senado, proposto pelos Presidente e Relator da CPI sobre a questão populacional, mas arquivado. 
Sugerindo um primeiro momento de confronto inter-ministérios esse acontecimento é revelador do isolamento em que é colocado o Ministério da Saúde nessa proposta. Atesta o fato o seguinte depoimento do Ministro Waldir Arcoverde, em relação ao assunto, veiculado na mesma matéria: "... o Ministro da Saúde, Waldir Arcoverde, disse... que desconhece o decreto governamental anunciado por Waldir Vasconcelos. Este decreto não passou pelo Ministério da Saúde, assegurou o Ministro. Ele lembrou que a competência para estabelecer uma política de planejamento familiar está diretamente ligada à sua pasta. Arcoverde não quis fazer mais declarações sobre o tema, alegando que a imprensa estava propondo uma intriga entre ele e Vasconcelos...".

Indicador da presença de uma luta político-ideológica, calcada em interesses econômicos e travada no interior do próprio Estado, esse confronto se apresenta, não somente em termos do posicionamento frente à interferência, ou não, do Estado nos assuntos privados da família (no caso, a decisão pelo número da prole), mas, sobretudo, em termos de um confronto de esferas de competência entre o Ministério da Saúde e o Estado Maior das Forças Armadas (EMFA) para a definição e assunção da condução de uma política de planejamento familiar entendida, por um lado, como política social de saúde e, por outro, como política demográfica e de segurança nacional.

Constituindo-se na marca característica da conjuntura a partir de 1984, esse tipo de enfrentamento se materializa, alternativamente no período, incorporando a mobilização ativa de setores da Sociedade Civil, ora na defesa de uma política de planejamento familiar inscrita no Programa de Assistência Integral à Saúde da Mulher (PAISM), conforme o referido posicionamento do Ministério da Saúde assumido na Conferência Mundial de População, na Cidade do México, no ano de 1984, ora na busca de definição de uma política de controle da natalidade para o país $^{3}$. (MINISTÉRIO DA SAÚDE, 1983a;b)

Para ilustrar como esse tipo de confronto se deu até 1993, de forma a caracterizar a posição ambígua do Estado Brasileiro frente à Política de Planejamento Familiar, o desdobramento desse primeiro episódio entre os ministros Waldir Arcoverde e Waldir Vasconcelos, que culmina com a definição do texto constante no Artigo 226 da Carta Constitucional de 1988, é bastante esclarecedor.

3 Vale lembrar que como representantes do primeiro grupo destacam-se, além de entidades feministas, sindicatos, entidades políticas e intelectuais, a Associação Brasileira de Estudos Populacionais (ABEP) e o Conselho da Condição Feminina da Secretaria do Interior do Estado de Sôo Paulo, com importante atuação. Na vertente controlista colocam-se, dentre outras, entidades como a Federação das Indústrias, a Academia Nacional de Medicina e a BENFAM. 
Assim, ao aparente recuo dessa tendência controlista, com o arquivamento, em 1984, do referido Projeto de Lei N. $.267 / 84$ do Senado, manifesta-se o aparente fortalecimento da proposta do Ministério da Saúde com a criação, em setembro de 1985, da Comissão de Estudos sobre Direitos da Reprodução Humana (CEDRH), presidida por Ruth Escobar (PMDB/SP).

Essa dupla face da aparência, caracterizada por sucessivos avanços e recuos de ambas as tendências em diferentes momentos dessa conjuntura do pós 1984, é revelada ou posta de maneira explícita, pelo reconhecimento público da existência de uma indefinição de tal política sendo, essa indefinição, título da seguinte matéria veiculada pelo Matutino Paulista, a Folha de São Paulo, em 11-01-1986, p. 21: "Enquanto não for institucionalizada uma política de planejamento familiar no país, as mulheres carentes em idade fértil correm o risco de servir de cobaias em testes de novos anticoncepcionais. Esse quadro pouco animador é do conhecimento do Ministro da Saúde, Carlos Sant'ana, ...: que não dispõe de instrumentos legais para combater abusos praticados em nome do planejamento familiar. O Ministro [continua o noticiário] acaba de encaminhar ao Presidente Sarney um documento em que defende o direito do casal a ter acesso a todas as informações e poder decidir sobre o número de filhos desejados. Afirma [o Ministro] que o planejamento [familiar] é um assunto de saúde, dizendo ser inadmissivel fazer do controle populacional a solução mágica dos problemas que afligem a humanidade".

Reveladora do nível de resistência colocado a essa proposição do Ministério da Saúde encontra-se a seguinte afirmação, também veiculada na mesma matéria acerca da indefinição da política de planejamento familiar: "Mas a defesa do planejamento familiar como parte integrante do atendimento público à saúde, incorporado aos serviços públicos federais, estaduais e municipais, não significa que esta será a política adotada. A posição do Ministro está em desacordo com o que defende o "Grupo de Parlamentares para o Estudo da População e Desenvolvimento", da qual fazem parte 20 Senadores, 267 Deputados Federais e 197 Deputados Estaduais. Para o grupo [afirma o Matutino] a questão do planejamento familiar não deve ser de competência do Ministério da Saúde, mas de um novo organismo, o ConseIho Nacional de População e Planejamento Familiar, a ser supervisionado pelo Presidente da República e composto por entidades privadas, que poderá obter recursos junto a entidades internacionais, desde que não interfira diretamente na política populacional brasileira".

No entanto, a despeito desta controvérsia, cerca de quatro meses depois, em maio de 1986, o avanço da proposta do Ministério da saúde parecia revelar-se de maneira decisiva com a implantação, por um lado, do Programa de Assistência Integral à Saúde da Mulher pelo INAMPS (Instituto Nacional de Assistência Médica e Previdência Social), sob a presidência 
do Professor Hésio Cordeiro. Por outro, com a adesão da Igreja ao referido Programa do INAMPS, com a orientação, através da CENPLAFAM ${ }^{4}$. dos meios contraceptivos naturais.

Nesse contexto, longe de recuar, o que se observa é a manifestação, de janeiro a março de 1987, de um significativo avanço da tendência "controlista" representado numa tentativa de ampla mobilização com vistas à Constituinte de 1988. Fato notório é a divulgação, pelo próprio Governo, da existência de proposta de criação de uma política de controle da natalidade, também denominada controle familiar, nascida de uma reunião do Conselho de Desenvolvimento Social (CDS), órgão criado em 1974, por ocasião do período de transição. Segundo informação foi designada, na citada reunião, uma Comissão Interministerial, coordenada pelo Ministro-chefe do Gabinete Civil, Marco Maciel, compreendendo os seguintes Ministérios: Saúde, Previdência e Assistência Social, Planejamento, Trabalho, Educação, Justiça, Interior, Ciência e Tecnologia, Desenvolvimento Urbano, além do Ministro-chefe do Gabinete Militar.

Longe de estranhar a presença do Ministério da Saúde, e também da Previdência e Assistência Social, na defesa de uma política de controle da natalidade como política nacional, vale mencionar as pressões existentes, nesse período, para a assunção de uma política demográfica no país, por considerável parte de setores do governo.

llustra o fato, "Relatório Crítico" apresentado pela Comissão de Estudos sobre Direitos da Reprodução Humana (CEDRH), criada em 1985 e vinculada ao próprio Ministério da Saúde, sobre documento apresentado pelo Ministro da Saúde, Roberto Santos, em junho de 1986, em reunião da Comissão de Saúde da Câmara de Deputados, intitulado " $O$ Ministério da Saúde e a Questão do Planejamento Familiar".

Segundo o Relatório, a postura do Ministro da Saúde era "muito cautelosa" em decorrência do emaranhado de interesses, internos e externos, que envolviam a questão (Folha de São Paulo, 07-09-1986, p. 24).

Em relação ao então Ministro da Previdência e Assistência Social, Rafael de Almeida Magalhães, vale revelar que sua posição era contrária ao do próprio programa desenvolvido pela sua pasta, através do INAMPS, presidido na ocasião pelo Professor Hésio Cordeiro.

A ampla mobilização de vários segmentos da sociedade civil não se fez tardar em defesa de uma política de planejamento familiar, que se contrapunha ao controle de natalidade, trazendo, para o interior da própria Comissão Interministerial, grande debate. Centrou

4. Esta sigla refere-se à Confederação Nacional de Centros de Planejamento Familiar, entidade ligada à Confederação Nacional dos Bispos do Brasil (CNBB). 
seus argumentos sobretudo na tendência à queda da taxa de crescimento demográfico no país (de 2,9\%, em 1950 a 2,0\%, em 1980) e denunciou interesses internacionais que presidiram o financiamento de programas de controle demográfico no país, no período de 1979 a 1983, com a injeção de cerca de 35 milhões de dólares em programas denominados de "planejamento familiar".

Como resultado, a referida Comissão Interministerial recuou na sua proposta inicial decidindo descartar o controle de natalidade e optar por informar a mulher acerca dos métodos contraceptivos. (Folha de São Paulo, 27-03-1987, p. 16)

Essa ampla mobilização teve, finalmente, registrada a sua marca na Carta Constitucional, onde a questão reprodutiva, circunscrita ao parágrafo $7^{\circ}$ do Artigo 226 , apresenta-se sob a forma de "Planejamento Familiar" como um direito acessível voluntariamente a todos, descritos nos seguintes termos: "Fundado nos princípios da dignidade da pessoa humana e da paternidade responsável, o planejamento familiar é livre decisão do casal, competindo ao Estado propiciar recursos educacionais e científicos para o exercício desse direito, vedada qualquer forma coercitiva por parte de instituições oficiais ou privadas”.(CONSTITUIÇÃO DA REPÚBLICA FEDERATIVA DO BRASIL, 1998, p. 133)

Colocado, assim, à guisa de exemplificação, esse movimento típico, que marca o período de 1984 a 1988, apresenta-se, por assim dizer, como uma das diferentes formas sob as quais a ambigüidade e indefinição da política do Estado Brasileiro no setor veio se manifestando no período pós 88 , a despeito do que reza o texto Constitucional.

Assim, longe de arrefecer, esse processo continua evidenciando, na conjuntura, senão a ausência de uma política de planejamento familiar institucionalizada para todo o país - malgrado o avanço alcançado em alguns Estados como o de São Paulo -, uma indefinição da mesma, o que faz com que diferentes modalidades de planejamento e controle da prole tenham lugar no país, em função da diversidade de interesses gerais internos e externos - e de especificidades das realidades regionais.

Ilustra igualmente esse confronto de idéias e de interesses a forma como a questão foi introduzida na Conferência das Nações Unidas sobre Meio Ambiente e desenvolvimento, a Rio-92, que aconteceu no país.

Por um lado, a posição dos países desenvolvidos. A Comunidade Européia e Estados Unidos à frente, lutaram ao longo de toda a ECO-92 para que a Agenda 21 fizesse referência à necessidade de planejamento familiar para o Terceiro Mundo. O Relatório do Banco Mundial divulgado em 29 de maio na referida Reunião (Folha de São Paulo, 30-06-1992, p.3) "recomenda a países da América Latina e Caribe a adoção de políticas 
de planejamento familiar para diminuir problemas ambientais como destruição de florestas e degradação dos solos". Traduzindo os reais interesses desse Relatório o Chefe da Divisão de Meio ambiente para a América Latina do Banco Mundial, Dennis Mahar afirma que "a instituição receberia muito bem uma eventual proposta do governo brasileiro para o financiamento de um programa de controle da natalidade".

Por outro, os discursos dos líderes dos países do Terceiro Mundo procuraram evitar referências explícitas ao tema.

Em relação ao Brasil vale registrar a tentativa de uma posição oficial do governo brasileiro, contrária a dos países desenvolvidos que buscaram atrelar ao tema da Conferência à questão do crescimento demográfico e controle e conservação do meio ambiente.

Em matéria publicada sob o título "A questão populacional e a Rio-92" o Jornal Folha de São Paulo divulga, em 08-06-1992, p. 3, discurso do próprio Presidente da República do Brasil, Fernando Affonso Collor de Mello, que procura não só explicitar a controvérsia em torno do tema, mas igualmente colocá-la como um falso problema, se analisada dentro de uma postura puramente demográfica. Afirma que "a questão populacional não pode ser tratada nem como uma preocupação de segurança [nacional], nem como um mero exercício aritmético". Continua que "devemos deixar de encará-lo [o crescimento populacional] a partir de seus efeitos e passar a considerar suas causas [sendo] a principal destas... certamente a pobreza em que ainda sobrevive a maior parte da humanida$d e$ ". Finaliza firmando sua posição nos seguintes termos: “... o Governo Brasileiro pretende levantar o tema populacional na Rio-92 para que o mesmo faça parte, com destaque, da ampla reflexão que desejamos construir para o $3^{\circ}$ milênio. Nossa proposta será no sentido de que a questão demográfica seja tratada menos como problema ambiental, $e$ mais como um problema de desenvolvimento, como um desafio que todos temos a necessidade prática e moral de assumir, propondo soluções que aproximam os povos e favoreçam a justiça, o bem estar e a paz universal".

Posição contrária no entanto, foi a do próprio empresariado paulista, representado pelas figuras de Antônio Ermírio de Moraes e Mário Amato, que vêem no crescimento demográfico a causa determinante da pobreza do povo brasileiro e subdesenvolvimento da nação. Sob os títulos "A primeira Prioridade" (Folha de São Paulo, 3-05-1992, p. 3) e "Paternidade Responsável" (Folha de São Paulo, 1-06-1992, p. 3), esses autores, enquanto "sujeitos sociais", recolocam em cena, respectivamente, a vertente demográfica que vê no controle populacional a saída para os impasses econômico-político e social vivido pela sociedade brasileira e que se contrapõem, portanto, a uma postura de política social que incorpora uma visão ampla de planejamento familiar em saúde. 


\section{A CONJUNTURA PÓs 1993}

O ano de 1994 anuncia, em nível da mídia, os primórdios de uma nova conjuntura por trazer ao palco das discussões públicas não mais a ênfase na consagrada polêmica planejamento familiar versus controle da natalidade, mas por centrar as questões da regulação da fecundidade em problemas específicos, polêmicos e relevantes para a saúde da mulher, quais sejam, a descriminalização e legalização do aborto e a regulamentação, pelo Estado, da esterilização feminina e masculina como método reconhecidamente oficial a ser oferecido nos serviços do Sistema Único de Saúde (SUS).

Assim, embora as questões do aborto voluntário e da esterilização feminina representem, no Brasil, discussões antigas e permeiem toda a polêmica em torno da política de contracepção no país, amplamente veiculada pela média desde a década de 80 é, sobretudo a partir de 1994, que ambas passam a ocupar papel de destaque no país. Neste sentido, o trabalho de Jacira MELO (1997), intitulado "A polêmica do aborto na imprensa", é exemplo típico dessa tendência.

Em relação ao aborto, aspecto a observar é o de que desde a década de 80, um dos pontos importantes quando se fala em reforma do Código Penal, é segundo Leila Linhares BASTERD (1998, p. 16), a tentativa de diálogo das mulheres "com o Estado, em particular com o Poder Legislativo, para descriminalizar o aborto voluntário ou mesmo tornar a legislação penal menos repressora através da ampliação dos permissivos legais para a interrupção da gravidez com consentimento da mulher".

Este fato é constatado por ROCHA quando afirma: "no decorrer do processo constituinte em que o assunto aborto era um dos temas polêmicos, mesmo a parte do movimento de mulheres que insistia na importância de uma explicitação constitucional sobre $o$ tema acabou acordando com parlamentares progressistas que a questão do aborto não deveria ser matéria constitucional. [Salienta] a importância do papel desempenhado pelo Conselho Nacional dos Direitos da Mulher neste posicionamento político"(ROCHA, 1996, p. 392).

Nesta década vale destacar a criação do Conselho Nacional dos Direitos da MuIher (CNDM), com sede no Ministério da Justiça e congregando, segundo HARDY \& REBELLO (1996, p. 263), "mulheres com diferentes ideologias e objetivos" e para o qual "convergiram as reivindicações dos grupos organizados de mulheres". Na década de 90 não foi outra senão a tendência à intensificação desse movimento, explicitado no trabalho de ROCHA (1996, p. 392) quando afirma: 
"No âmbito das atividades ordinárias do Congresso, foi nos primeiros anos da década de 90 ... que se intensificou a influência do movimento feminista. De alguma maneira, sob essa influência, pode-se situar o conjunto de cinco projetos de lei de Eduardo Jorge, alguns deles em co-autoria com Sanda Starling; a reapresentação do projeto de lei de José Genoino sobre a matéria; $e$, principalmente, o projeto substitutivo da deputada Fátima Pelaes. $\boldsymbol{A}$ influência do movimento feminista se fez ainda mais presente em duas proposições, ambas apresentadas por parlamentares feministas: o projeto substitutivo da deputada Jandira Feghali e o projeto de lei da senadora Eva Blay. Estas parlamentares, neste contexto da discussão, realizaram no Congresso, em diferentes ocasiões, dois seminários e uma audiência pública. Através destas atividades buscaram ampliar a interlocução sobre o tema, não somente no próprio Parlamento, como também com vários segmentos da sociedade".

Além desta intensificação observada por Rocha pode ser acrescentado o que Danielle ARDALLON $(1998$, p. 3) caracteriza como transformações de natureza qualitativa, no interior da sociedade inclusiva. Para ela são "visíveis às mudanças positivas na qualidade do debate, bem como no adensamento das argumentações a favor, senão de uma descriminalização do aborto, certamente de uma ampliação da tolerância para a sua legalização".

Buscando explicar tais mudanças coloca, ao lado da ação do movimento feminino, sobretudo o contexto político de democratização crescente da sociedade brasileira onde este movimento se inscreve, assim como a presença de uma nova consciência cívica, inaugurada com o impeachment do Presidente Fernando Collor de Mello, que redefine novos valores ético-morais em relação ao aborto, capaz de comportar a crítica de um "Ministro da Justiça contra a "hipocrisia" da lei (Maurício Corrêa, em Veja, 10/92), seguidas pela notícia da primeira sentença de um juiz autorizando um aborto por anomalia fetal (12/92)...". (ARDALLON, 1998, p. 3)

No entanto, na medida em que a discussão do aborto, como questão pública, ganha espaço significativo na mídia brasileira, notadamente a partir de 1994, tal fato permite, nesse contexto de progressiva democratização da sociedade brasileira, tomar a Conferência do Cairo como marco de uma nova conjuntura caracterizada pelas possibilidades de busca de amplificação dos direitos da mulher à luz do princípio básico norteador da mesma, os direitos reprodutivos.

A explicação para o deslocamento observado da discussão da questão reprodutiva na mídia brasileira, que permite caracterizar duas conjunturas distintas, a de 1984 a 1993 e a pós 1993, encontra sustentação no trabalho de BERQUÓ (1998) quando de sua análise das pautas de discussão que nortearam e caracterizaram as várias conferências 
sobre população anteriores à "Conferência Internacional sobre População e Desenvolvimento", realizada na cidade do Cairo, Egito, em 1994, centradas, segundo ela, basicamente na questão do controle da natalidade ou planejamento familiar.

De acordo com a referida autora,

"O documento do Cairo reflete com bastante clareza a agenda de prioridades que as mulheres de todo o mundo, através de suas redes de lideranças, foram construindo durante os anos de preparação da Conferência. São elas que reorientam o eixo da questão populacional, ao colocarem a regulação da fecundidade no plano dos direitos individuais. Como consequência, o planejamento familiar, stritu sensu, perde status, e surge no Cairo a consagração dos direitos reprodutivos". (BERQUÓ, 1998, p. 26)

Tal estratégia explica o aprofundamento que as questões reprodutivas alcançam na referida Conferência. Nela, o conceito de "Saúde Reprodutiva", apontando para a integralidade dos fenômenos reprodutivos, ganha expressão crescente no campo da Saúde Pública não somente por melhor incorporar velhos e novos problemas relacionados à saúde e reprodução mas, sobretudo, por pressupor, segundo FIGUEROA PEREA (1977), pelos princípios que o embasam, a necessidade destes serem enfocados no contexto de determinadas relações sócio-culturais, políticas e econômicas, características de diferentes realidades sociais.

Assim é que, ao ser definido na Conferência do Cairo (1994) como o "estado de completo bem estar físico, mental e social, e não somente a ausência de doença, em todas as áreas relacionadas com o sistema reprodutivo, suas funções e processos", o conceito de Saúde Reprodutiva, empregado desde a década dos anos 80 , ganha maior amplitude quer em nível teórico, quer em nível da prática e passa a caracterizar uma nova área do campo da Saúde Pública, com implicações para a definição de políticas de saúde no setor.

Pela natureza dos problemas abordados na Conferência e por defender, como principios básicos, os direitos sexuais e reprodutivos da mulher, o conceito de Saúde Reprodutiva norteia-se pelos princípios de igualdade e de equidade de gênero. Daí a tônica da discussão girar especialmente em torno de questões como a dos direitos da mulher ao seu corpo, das relações da opressão masculina, do "empoderamento da mulher". Por isso, a grande questão controvertida no Cairo 94 ter sido a da sexualidade e do aborto como livre opção da mulher, que opôs posições progressistas como a do Brasil e de outros países à do Vaticano e dos Fundamentalistas Islâmicos, conforme explicita matéria do Jornal do Brasil de 11/9/994, p. 12 , intitulada "ONU vota aborto com abstenção do Vaticano".

"A Conferência Internacional das Nações Unidas sobre População e Desenvolvimento abriu oficialmente segunda-feira, no Cairo, as discussões sobre as políticas de 
controle populacional a serem aplicadas no próximos 20 anos no mundo. Os mais de 180 países que participam do encontro deverão, até dia 13, aprovar um Programa de Ação.

O ponto mais polêmico do documento da ONU apresentado aos países participantes para discussão está nos parágrafos que fazem referência ao aborto e à assistência às mulheres que abortam. O Vaticano e alguns países católicos, de um lado, e vários países islâmicos, de outro, criticaram o documento, que julgaram permissivo. A recusa da Santa Sé a aprovar o texto levou a uma reformulação dos parágrafos mais polêmicos.

Sexta-feira, depois da terceira modificação no texto original, que visava a dar respostas às críticas católicas, o Comitê Principal aprovou o documento. O Vaticano e a Jordânia se abstiveram da votação, enquanto Argentina, Malta e Equador expressaram reservas em relação ao texto. O porta-voz do Vaticano, Joaquim Navarro-Vals, explicou que, ao se abster, a Santa Sé não mudou sua posição".

A posição avançada do documento da ONU e da posição defendida por vários países, inclusive o Brasil, pode ser expressa por matéria de Kristina Michahelles, enviada especial do Jornal do Brasil, em matéria de 11/9/1994, p. 26, quando enuncia, em nível do título, que "População tem abordagem humana no Cairo [e] Conferência Mundial avança ao substituir estatísticas demográficas pelo debate sobre melhoria da qualidade de vida do homem", diferentemente do que ocorreu nas reuniões anteriores realizadas em Bucareste (1974) e no México (1984).

Sustentando tal asserção, a referida matéria trata da questão nos seguintes termos: "Esta nova abordagem inclui o desenvolvimento sustentável, a pobreza, o excesso de consumo. A urgência de examinar novos caminhos para gerir o planeta recebeu o aval de mais de cem chefes do Estado na Rio-92. O processo continua com a reunião do Cairo, e prosseguirá em março com novo encontro na agenda da ONU: uma conferência dedicada à mulher em Pequim, em 1995.

O Cairo tornou novas dimensões mais transparentes. Os recursos e o acesso mais democrático dos cidadãos a um conjunto de serviços, em especial ao planejamento familiar, contra um pano de fundo de conviç̧ões culturais e religiosas tornou necessário rediscutir a função social da mulher. Pois, como definiu Nasreen Huq, de Bangladesh, "mulheres têm filhos, e não população". As emocionantes histórias individuais, as questões dogmáticas das religiões e os frios números dos tecnocratas... mostram quanto esforço será necessário para colocar em prática o Programa de Ação que vai ser adotado na terça-feira. A Conferência do Cairo é um teste de maturidade". 
Quanto aos resultados da Conferência, a matéria de 11/9/1994, p. 3-4, assinada por Hélio Schwartsman, enviado especial ao Cairo do Jornal Folha de São Paulo, ganha expressão ao afirmar, em nível do título: "Encontro revoluciona direitos humanos: Conferência do Cairo sobre população consagra educação sexual e afirmação dos direitos da mulher".

Segundo a referida matéria, "Apesar de todas as complexas negociações em torno dos pontos mais polêmicos, como aborto, definição dos direitos reprodutivos, educação sexual para adolescentes etc., pode-se dizer que a maioria dos países estavam de acordo, já nas conferências preparatórias, com cerca de 90\% do documento".

O avanço representado pela Conferência, como resultado final do embate de forças entre progressistas, tradicionalistas e ortodóxos, é bem expressado na manchete do Jornal do Brasil de 14/9/1994, p. 14, quando afirma que "Reunião do Cairo acaba com acordo histórico - Programa de ação teve apoio inédito do Vaticano para orientar o crescimento populacional no planeta nos próximos 20 anos", isto porque, segundo a referida matéria, "pela primeira vez na História, o Vaticano aderiu (com reservas) ao consenso em torno de um documento das Nações Unidas sobre política populacional". As reservas mantidas referiram-se aos "termos contidos nos capítulos sétimo e oitavo, notadamente sobre o aborto, contracepção e educação sexual".

A importância desse consenso, assim como do avanço das posições assumidas pode ser observada em matéria do Jornal O Estado de São Paulo, de 14/9/94, p. A15, intitulada "Pobres e ricos chegam a consenso no Cairo", de Paulo Sotero, quando afirma: "Mais de 170 países aprovaram ontem, último dia da Conferência Mundial da ONU, Programa de Ação que defende políticas ousadas para proteger e promover a saúde sexual e reprodutiva da mulher". Destaca os seguintes pontos mais importantes do Programa de Ação aprovado na reunião:

“. Consagra os direitos reprodutivos da mulher e os equipara aos direitos humanos;

- Condena o aborto como método de planejamento familiar, mas o reconhece como uma importante questão de saúde pública;

. Estipula que a valorização econômica e social das mulheres, por meio da educação equiparável à dos homens, é a chave para o sucesso da estabilização do crescimento da população;

. As mulheres devem ter o poder de decisão sobre sua vida reprodutiva e os meios necessários para exercer esse poder;

. Fixa como metas: educação primária universal até 2015; remoção de todas as barreiras ao planejamento familiar até 2005; redução de um terço da taxa de mortalidade infantil até 2000; 
. Estabelece que os governos dos países industrializados terão de multiplicar por 7, nos próximos seis anos, a ajuda anual de US\$800 milhões que deram em 1993 ao programa de planejamento familiar e de saúde reprodutiva do Terceiro Mundo".

Em relação a posição da delegação brasileira, alguns membros ouvidos pela FoIha de São Paulo foram, segundo o referido "enviado" do Jornal, "unanimes em considerar o documento como peça muito importante", acrescentando:

"Destacam entre os pontos positivos a afirmação da sexualidade como um direito, a ênfase na necessidade de fortalecer o status da mulher ("empowerment of women") e de promover novos conceitos, como os de maternidade segura e direitos reprodutivos".

A posição "progressista" do Brasil e a participação ativa da delegação brasileira na Conferência mereceu elogio da diretora do Fundo das Nações Unidas para População, a médica paquistanesa Nafis Sadik, conforme relata matéria de 10/9/1994, p. 13, de Kristina Michahelles, correspondente do Jornal do Brasil:

"A delegação brasileira teve um papel muito importante nesta conferência. Se até pouco tempo ainda havia um claro divórcio entre a posição oficial e as organizações nãogovernamentais, no processo de preparação desta reunião o governo do Brasil soube integrar de forma exemplar as preocupações das organizações não-governamentais".

Acrescenta a enviada especial do referido matutino, na mesma matéria:

“O Brasil também fez intervenções importantes no trecho sobre migrações internacionais e contribuiu para as discussões sobre o polêmico artigo que trata do aborto. $A$ delegação oficial do Brasil no Cairo incluiu demógrafos respeitados como Elza Berquó, do CEBRAP, Donald Sawyer, do Instituto População e Sociedade, e Neide Patarra, da Associação Brasileira de Estudos da População, e representantes de ONGs ativas, como Jacqueline Pitanguy, da Comissão de Cidadania e Reprodução, e Rosiska Darcy de Oliveira, do Combatom (Coalização de Mulheres Brasileiras para a População e o Meio Ambiente)".

A integração de Jacqueline Pitanguy, diretora do CEPIA (Cidadania, Estudo, Informação e Ação), uma das mais importantes organizações feministas do Brasil, na delegação oficial do Brasil na Conferência demonstra, segundo matéria do Jomal da Tarde de 13/9/1994, p. 8B, que "muita coisa mudou nas relações entre o Itamaratye as ONGs brasileiras". Refere, ainda que "O embaixador Geraldo Holand Cavalcanti conversou no Cairo com representantes dessas organizações não governamentais e chegou a participar ativamente de suas reuniões". Por isso, de maneira significativa, a matéria é intitulada "ONGS influenciam posição do governo".

Diante disso, é possível entender porque a conjuntura PÓS 93 encontra espaço propício no Brasil para o deslocamento da discussão planejamento familiar versus controle 
da natalidade para temas polêmicos como a descriminalização do aborto e a regulamentação, pelo Estado, da esterilização feminina e masculina, na medida em que a discussão dos mesmos inscreve-se no contexto dos "direitos sexuais e reprodutivos" firmados pelo Programa de Ação aprovado na Conferência de Cairo. Por outro lado, vale destacar que esse avanço do movimento feminista foi reafirmado, e mesmo ampliado, na "declaração" aprovada pela "IV Conferência Mundial da Mulher", realizada em setembro de 1995, em Pequim, ano do cinqüentenário da Fundação das Nações unidas (Folha de São Paulo, 16/9/94, p. 2).

No entanto, a exemplo da polêmica planejamento familiar versus controle da natalidade que defendia não somente tipos de políticas diferenciais, social versus demográfica, mas diferentes interesses econômico-ideológicos, no caso da esterilização e, sobretudo do aborto, questões ético-morais e religiosas se lhe acrescentam e colocam no palco do embate de forças que se trava ao longo dos últimos anos uma acirrada controvérsia em torno da legalização e ou descriminalização do aborto e da esterilização masculina e feminina.

Diante da riqueza que o tratamento dos temas comportam, o objetivo no presente trabalho é, tão somente, o de centrar o enfoque em algumas evidências que permitam ilustrar a natureza da controvérsia e reter em que nível a presença do Estado neoliberal, numa sociedade que caminha para a democratização como a brasileira, controla a existência familiar via intervenção nos direitos reprodutivos da mulher, a despeito dos compromissos assumidos na Conferência do Cairo e Pequim.

Assim é que, se por um lado, na presente conjuntura, "a situação mudou tanto no judiciário, como na Igreja Católica", a mesma tendência não foi observada "do lado dos parlamentare s da esquerda", conforme afirma ARDAILLON (1998, p.4).

Fato significativo foi a "manobra política para tornar o aborto totalmente ilegal", segundo o jornalista José Casado, em matéria intitulada "Mulheres em perigo", do Jornal $O$ Estado de São Paulo, de 2/12/95, p. A4. Segundo o jornalista, esta refere-se a um projeto de emenda constitucional que levou o ${ }^{\circ} 25-\mathrm{A}$, do deputado Severino Cavalcante, do PFL de Pernambuco. "Lider evangélico"... e "embalado pela banda de música fundamentalista do bloco evangélico", que somava na época 47 votos no congresso, seu projeto propunha mudança na garantia do direito à vida (artigo $5^{\circ}$ da Constituição) sugerindo a inserção da expressão "desde a concepção" o que, segundo José Casado, "detonaria o trecho do Código Penal (artigo 128) onde se prevê permissão ao aborto nos casos de gravidez por estupro e de risco de vida para a gestante".

Ao buscar analisar o significado da proposta, este ornalista coloca em cena o movimento evangélico como importante força não somente dentro do Congresso Nacional, mas da sociedade inclusiva, ao afirmar: 
"Ao entusiasmo da facção mais radical da bancada evangélica soma-se a discretíssima omissão da Igreja Católica. Há um confronto latente no espaço pastorial, com evidente avanço do movimento evangélico ... como força religiosa e política" ( $O$ Estado de São Paulo, 1995, p. 4).

Vale destacar que a referida emenda constitucional chegou a ser aprovada pela CCJ (Comissão de Constituição e Justiça) da Câmara dos Deputados.

Diante do firme e amplo posicionamento do movimento feminista e de mulheres parlamentares a referida emenda foi rejeitada de maneira representativa.

A posição assumida por Jacqueline Pitangui no debate travado em torno da rejeição desta proposição é bastante exemplificadora, do ponto de vista interpretativo, por demonstrar, de maneira substantiva, como a questão do Estado neoliberal, a despeito de suas características e dos avanços do processo de democratização da sociedade brasileira, interfere no privado (individual e familiar) de maneira autocrática. Segundo a mesma,

"O Estado brasileiro exibe sintomas graves de uma espécie de esquizofrenia sempre que se trata de discutir os direitos da mulher. No momento, eles se manifestam visivelmente na comissão especial da Câmara dos Deputados que examina a proposta de emenda constitucional que, a pretexto de defesa da vida, proibe o aborto em qualquer circunstância, mesmo nos casos hoje previstos em lei. A esquizofrenia está em pretender que o Estado retire das mulheres direitos adquiridos e consagrados em várias convenções internacionais que o Brasil subscreveu, com isso contrariando posições que ele próprio assumiu".

Em um dos seus argumentos afirma que

"No caso presente, a intenção de impedir que, mesmo nos eventos já previstos em lei .... a mulher possa decidir pela interrupção ou continuidade da gravidez, se insere na tradição mais ampla do Estado brasileiro de tratar a mulher como incapaz de tomar decisões e atuar como sujeito do próprio destino". [Para ela] A emenda constitucional, se aprovada, reforçaria o domínio autoritário do Estado sobre o cidadão, num momento em que justamente a sociedade mais se bate pela afirmação, e não pela restrição dos direitos individuais". (O Estado de São Paulo, 8/12/1995, p. A2)

Conclui com um argumento altamente relevante para a questão dos direitos reprodutivos, igualdade e equidade de gênero, que enuncia nos seguintes termos:

"... a emenda em tramitação no Congresso contraria frontalmente uma série de compromissos internacionais assumidos pelo Brasil, a começar pela Convenção contra todas as formas de discriminação contra a mulher (ONU, 1979). Tornar crime uma prática 
médica que só e usada pelas mulheres seria uma clara forma de discriminação". ( $O$ Estado de São Paulo, 8/12/1995, p. A2)

Diante de tais reflexões podemos melhor entender e contextuar a posição assumida por ARDAILLON (1998, p. 4) quando assevera que a inclusão, no início de 1988, por parte da Comissão Especial do Ministério de Justiça para a reforma do Código Penal, de um terceiro permissivo, em sua proposta final, que autoriza o aborto conquanto haja "fundada probabilidade, atestada por dois outros médicos, de o nascituro apresentar graves e irreversíveis anomalias" não representa avanço porque "só faz referendar uma prática existente que beneficia os profissionais da medicina fetal e algumas gestantes desafortunadas, mas pouco alarga a autonomia sexual do conjunto das brasileiras".

Frente aos impasses que a busca da legalização, ou mesmo descriminalização do aborto vem sofrendo é de se esperar, como afirma ROCHA (1998, p. 51) que "as mudanças legislativas, nesta área, ocorrerão de modo gradual", a despeito do Brasil ter sido signatário, sem reservas da carta de compromissos, tanto da Conferência de Cairo 95, quanto da de Pequim 95.

Neste sentido, o importante a destacar é que para a garantia desse avanço, ainda que gradual, a integração Estado-sociedade civil apresenta-se como condição necessária.

Para tanto, a garantia de espaços institucionais de atuação em prol dos Direitos Reprodutivos, como os assumidos por órgãos como o Conselho Nacional dos Direitos da Mulher (CNDM), do Ministério da Justiça, ao lado da Comissão Nacional de População e Desenvolvimento (CNPD), criada em agosto de 1995 pelo decreto $n^{\circ} 1607$ do Sr. Presidente da República com a finalidade de contribuir para a formulação de políticas e implementação de ações integradas relativas à população e ao desenvolvimento, torna-se fundamental.

Como representante do movimento feminista cabe salentar a relevância da atuação política da Rede Nacional Feminista de Saúde e Direitos Reprodutivos, fundada em 1991 como resultado de uma ampla articulação do movimento de mulheres do Brasil, igualmente destacada por BERQUÓ $(1988$, p. 3) não somente pela "atuação marcante ... durante a preparação para o Cairo ... mas [igualmente] porque orienta seu trabalho em torno de três eixos principais que guardam estreita relação com as recomendações do Plano de Ação: a conceituação de direitos reprodutivos e sexuais como direitos humanos; a retomada do Programa de Assistência Integral à Saúde da Mulher [PAISM], como referência para a otimização dos serviços; a luta pelo direito ao aborto ... levando em conta .... em todas as abordagens ... recortes de gênero, raça, etnia, classe e orientação sexual". 
Igualmente importante é considerar a entrada em cena, como sujeito social, o grupo de católicos feministas, com representação em vários países, que tem se colocado de maneira explicita contra a posição conservadora do Vaticano e vem apresentando, no Brasil, atuação significativa. Sob o lema "Católicas pelo direito de decidir", o movimento vem lutando pelo "direito e autonomia no campo reprodutivo" (MELO, 1997, p. 410) tendo apresentado, por ocasião de visita do Papa ao Brasil, "carta aberta" visando a reivindicação dos direitos da mulher, reproduzida no Dossiê Aborto da revista Estudos Feministas (1997, p. 418-22).

Considerando que "os principais fatos noticiosos que colocaram o tema do aborto nas primeiras páginas dos jornais [sobretudo nos anos 1996 e 1997] estão os projetos [sobre o aborto], em tramitação no Congresso" (MELO, 1997, p.409), é de se esperar que a atuação das mulheres parlamentares, feministas ou afinizadas com a causa defendida pelo movimento, tenha papel importante para a continuidade da luta e obtenção de conquistas no campo dos direitos reprodutivos.

Em relação à esterilização cirúrgica grande foi a polêmica gerada, desde a década de 80 , com o aumento gradativo que a mesma veio assumindo como método de controle da fecundidade no país, inclusive, segundo matéria da Folha de São Paulo de 30/1/89, p. C-6, paga por capital estrangeiro, de acordo com afirmação de José Aristodemo Pinotti, então Secretário da Saúde do Estado de São Paulo.

A ampla mobilização em torno da questão representou o mesmo tipo de debate gerado em relação à polêmica planejamento familiar versus controle da natalidade característica da conjuntura 1984-1993, uma vez que por se caracterizar como método definitivo e defendido por organismos internacionais, tradicionalmente defensores de políticas demográficas de cunho controlista sofria, por parte do movimento feminista e setores progressistas do governo, forte rejeição ou grandes reservas.

A tendência à mudança desta posição decorreu da constatação do excesso de cesárias relacionadas à esterilização feminina, fato através do qual o Brasil foi considerado por BERQUÓ (1993), em trabalho apresentado em reunião preparatória para a elaboração do documento oficial a ser encaminhado para a Conferência do Cairo 94, como caso exemplar.

Assim, embora já existisse na Câmara o projeto de 209/91 e 114/94 (Senado), desde o início da década dos anos 90 tal projeto foi, segundo ROCHA (1998, p. 45) "muitas vezes objeto de polêmicas discussões na Câmara e no Senado - além de objeto de um voto parcial do próprio Executivo - sendo finalmente aprovado e promulgado como lei, em sua totalidade, em agosto de 1977".

Segundo a mesma autora tal 
"projeto de lei se destacou ... porque foi uma iniciativa política de parlamentares progressistas, e identificados com as idéias do movimento feminista, que se dispuseram a enfrentar os abusos relativos à esterilização cirúrgica no país. Destacou-se, também, porque foi objeto de intenso debate relacionado a vários aspectos, mas, sobretudo, à questão ética da esterilização. [Nesse processo depararam também] com objeções morais da Igreja católica relativas ao uso deste procedimento anticoncepcional". (ROCHA, 1998, p. 45-6)

Como exemplo dessas objeções O Estado de São Paulo publica, em 24/6/94, p. A13 a seguinte matéria intitulada "CNBB vai tentar vetar projeto sobre esterilização" com o seguinte teor:

"Na tentativa de impedir sua aprovação pelo Senado, [o presidente da Conferência Nacional dos Bispos do Brasil (CNBB), d. Luciano Mendes de Almeida] ... disse que está disposto a fazer todas as gestões, inclusive com o presidente Itamar Franco, para evitar que os "valores éticos" defendidos pela Igreja sejam violados.

O presidente da CNBB esclareceu que a Igreja não é contra o planejamento familiar nem se opõe a decisão dos casais de não ter mais filhos, mas condena radicalmente os métodos artificiais".

Regulamentado o parágrafo $7^{\circ}$ do artigo 226 da Constituição Federal "essa lei prevê a esterilização cirúrgica para homens e mulheres com capacidade civil plena em maiores de vinte e cinco anos ou, pelo menos, com dois filhos vivos. Deve ser observado o prazo mínimo de sessenta dias entre a manifestação da vontade e o ato cirúrgico e, nas situações de exceção a este dispositivo, consideram-se o risco de vida da mulher ou do futuro concepto. E, por fim, veda a esterilização durante os períodos de parto ou ......, a não ser nos casos de comprovada necessidade, por cesárias sucessivas anteriores" (BRASIL. Congresso Nacional, 1996).

Embora essa lei represente, pelos princípios que a embasam, um avanço no campo da Saúde e dos Direitos Reprodutivos, uma vez que mulheres e homens passam a ter direito e acesso à laqueadura e à vasectomia, respectivamente, através do SUS, o fato a destacar é o de que, pelos interesses controlistas que sempre viram na esterilização cirúrgica estratégia privilegiada para o controle da fecundidade, a questão da vigilância para que a mesma não se caracterize como exclusiva das camadas pobres e se transforme em método preponderante, como quase já o é por ocupar atualmente o segundo lugar, é desafio fundamental para o movimento das mulheres.

Diante disso, e partindo da concepção de Madel LUZ (1979) de que "uma política pública é a que de fato ocorre no gozo de forças que define práticas e acomoda ideologias" 
preconizar, no contexto atual da sociedade brasileira, uma política contraceptiva como política social e não demográfica, inserida num programa de assistência integral à saúde de mulheres e homens para toda a sociedade brasileira, é projeto que se inscreve num devir de práticas democráticas não somente para o campo da saúde mas, sobretudo, para a sociedade inclusiva.

\section{REFERÊNCIAS BIBLIOGRÁFICAS}

ALVARENGA, A.T. de Política de Planejamento Familiar no Brasil. In: Anais do Simpósio Franco-Brasileiro sobre Prevenção da Mortalidade Materna com Ênfase na Gravidez na Adolescência". São Paulo: Departamento de Saúde Materno-Infantil da Faculdade de Saúde Pública da USP, 1992. p. 141-50. (Série Investigação em Saúde da Mulher, da Criança e Adolescência, 2).

ARAICA, A.H. De la estadística demográfica a la demografía política: otra transicion. In: WELTI, C. org. Población y desarrollo: una perspectiva latinoamericana después de el Cairo - 94. Mexico, PROLAP/UNAM, 1997. p. 25-64.

ARDAILLON, D. Da ilegalidade tolerada para a tolerância da legalidade. Jornal da redesaúde, 16:3-4, 1998.

BARROSO, C. A saúde da mulher no Brasil, 1975-1985. S. Paulo em Perspect., 2(1):25-33, 1986.

BERQUÓ, E. Brasil, uma caso exemplar: anticoncepção e partos cirúrgicos. Campinas, Núcleo de Estatística Populacional da UNICAMP, 1993. [Apresentado ao Seminário "A situação da mulher e o desenvolvimento", Campinas, 1993]

BERQUÓ, E. O Brasil e as recomendações do plano de ação do Cairo. In: BILAC, E.D. \& ROCHA, M.I.B. da (org) Saúde Reprodutiva na América Latina e no Caribe - Temas e Problemas. Campinas: PROLAP, ABEP, NEPO/UNICAMP/São Paulo: ed. 34, 1998, p. 23-35.

BRAGA, J.C. de S \& PAULA, S.G. de Saúde e previdência: estudos de política social. São Paulo, CEBES-HUCITEC, 1981.

BRASIL. Congresso Nacional. Relatório n ${ }^{\circ} 1 / 96$ da Comissão Mista relatora do veto presidencial ao PLC 114/94. Brasília: Centro Gráfico do Senado Federal, 1996, Apud ROCHA, M.I.B. da Significados Históricos e Políticos da Regulação da Fecundidade. In:BATISTA, C. \& LARANJEIRA, M. (org). Aborto: desafios da legalidade. Recife, SOS Corpo, 1998. p. 41-76 (Cadernos SOS Corpo, v. 2)

CANESQUI, A.M. A saúde da mulher em debate. Saúde em Debate, (15/16):29-36, 1984.

CANESQUI, A.M. A implantação e expansão dos serviços de planejamento familiar: questões e controvérsias. Rev. Paul. Enf., 5:26-30, 1985.

CARTA aberta por ocasião da visita do Papa ao Brasil. CDD-Católicas pelo direito de decidir. Estudos Feministas, 5(2):418-22, 1997. 
CONSTITUIÇÃO DA REPÚBLICA FEDERATIVA DO BRASIL (5 de outubro de 1988). São Paulo, Editora Atlas, 1998. v. 1, p. 133.

CORRÊA, S.\& PETCHESKY, R. Direitos sexuais e reprodutivos: uma perspectiva feminista. Physis: Rev. Saúde Coletiva, 6:147-77, 1996.

FIGUEROA PEREA, J.G. Elementos para definir una agenda de docência, investigación y análisis de políticas en el ámbito de la salud reproductiva. In: WELTI, C. org. Problación y desarrollo: una perspectiva latinoamericana después de el Cairo - 94. Mexico, PROLAP/UNAM, 1997. p. 159-201.

FIORI, J.L. \& KORNIS, G.E.M. Além da queda: economia e política numa década enviesada. In: GUIMARÃES, R. \& TAVARES, R. org. Saúde e sociedade no Brasil anos 80 . Rio de Janeiro, Relume Dumará, 1994. p-1-42.

HARDY, E. \& REBELLO, I. La discussion sobre el aborto provocado en el Congreso Nacional Brasileño: el papel del movimento de mujeres. Cad. SaúdePúbl., 12(2):25966, 1996.

LOPES, J.R.B. \& GOTTSCHALK, A. Recessão, pobreza e família: a década pior do que a perdida. S. Paulo em Perspect., 4(1), 1990.

LUZ, M.T. As instituições médicas no Brasil: instituição e estratégia de Legemonia. Rio de Janeiro, Ed. Graal, 1979.

MELO, J. A polêmica do aborto na imprensa. Estudos Feministas, 5(2):406-12, 1997.

MINISTÉRIO DA SAÚDE. Assistência integral à saúde da mulher: bases de ação programática. Brasília, Centro de Documentação do Ministério da Saúde, 1983a.

MINISTÉRIO DA SAÚDE Assistência integral à saúde da mulher; Pronunciamento do Ministro da Saúde, Interino, no encerramento Congresso Brasileiro de Proteção Materno-Infantil e Planejamento Familiar, 1o, Brasília, 1983, ANAIS. p:3-11, 1983b.

ROCHA, M.I.B. da O Parlamento e a questão democrática: um estudo do debate sobre controle da natalidade e planejamento familiar no Congresso Nacional. Campinas, NEPO-UNICAMP, 1987. (textos NEPO, 13).

ROCHA, M.I.B da Política populacional e planejamento familiar. S. Paulo em Perspect., 3(3):20-3, 1989.

ROCHA, M.I.B. da A questão do aborto no Brasil: o debate no Congresso. Estudos Feministas, 4(2):381-98, 1996.

ROCHA, M.I.B. da Significados históricos e políticos da regulação da fecundidade. In: BATISTA, C. \& LARANJEIRA, M. (org). Aborto: desafios da legalidade. Recife, SOS Corpo, 1998, p. 41-76 (Cadernos SOS Corpo, vol. 2).

WELTI, C. org. Población y desarrollo: uma perspectiva latinoamericana después de el Cairo-94. Mexico, PROLAP/UNAM, 1997. 
Summary: The present paper aims at characterising contraception as a public policy in Brazil from news matter published in two São Paulo's and one Rio's major daily newspapers. It tries to show how economic, political and ideological interests are present within the State it self and the civil society focusing the theme in a polemic way in the issue family planning versus birth control. Contraception as a public policy remains thus indefinite specially within 19841993. The polar discussion is re-defined after 93 with emphasis on principles defended in the Cairo Conference (1994) on reproductive rights and the right to decriminalized/legalised sterilisation and abortion.

Key words: contraception; family planning; birth control; woman health; reproductive health; induced abortion; tubal sterilization 